\title{
AN EVALUATION OF THE EFFECT OF A TRAINING PROGRAM ON WORKER LIFTING POSTURES
}

\author{
Don B. Chaffin, Leslie S. Gallay, Charles B. Woolley and Stephen R. Kuciemba \\ Center for Ergonomics, The University of Michigan, Ann Arbor, MI $48109-2117$ (U.S.A.)
}

(Received February 21, 1986; accepted May 19, 1986)

\begin{abstract}
Though worker training is often chosen as a means to reduce the risk of low back pain if involved in lifting activities, the effect on a worker's lifting posture is rarely reported. This paper describes a video analysis method of recording lifting postures and the results of one evaluation of a training program specifically
\end{abstract}

designed to modify lifting postures. It is concluded that a four-hour training program had beneficial but minor effects on the lifting techniques used by healthy workers in a warehouse when handling relatively light to moderate loads (i.e., $85 \%$ of loads lifted were below 30 pounds).

\section{INTRODUCTION}

Prevention of low-back pain has become a major challenge for health and safety officials in most industries. The annual cost to industry of low-back pain has been estimated in a recent study by Arthur D. Little to be $\$ 9$ billion, and in another study to be as high as $\$ 11$ billion (Snook and Jensen, 1984), and results in over 91 million days lost each year in the United States. Swedish data indicate that on any given day between $10 \%$ and $20 \%$ of the population will report some degree of low-back pain, within a one year period $40 \%$ to $50 \%$ of the population report they had low-back pain, and over a lifetime $50 \%$ to $70 \%$ of the population suffer from low-back pain (Biering-Sorenson, 1982). In most of these instances the pain is of relatively short duration and mild severity. In approximately
4\%, however, the pain continues with other symptoms and signs until the person is considered totally and permanently disabled.

Given the magnitude of the problem, many different prevention strategies are advocated in the literature. These usually can be classified into three groups:

(1) Ergonomically oriented redesign of the workplace and/or object to be handled in order to reduce low-back stresses.

(2) Improved medically based selection and placement procedures for workers involved in manual activities which could stress the lowback.

(3) Training of workers who perform manual activites in a manner that provides the knowledge necessary for them to change their work methods and postures and thus, reduce low-back stresses.

All three of these prevention strategies have 
their proponents in the literature. The current consensus appears to be that all three are necessary (NIOSH, 1981). Depending on the work requirements. organization structure, and certain worker population attributes, one strategy may be more effective than another.

Because low-back pain is often associated with an individual worker's activity (i.e., lifting a load, pushing a cart, etc.) the most popular single prevention strategy has been to emphasize training of the worker to perform the act in a safer manner.

Despite the variety of such training programs very few have been evaluated as to their effectiveness. Snook and White (1984) note that in some studies (Glover, 1976; Miller, 1977) a reduction in disability of up to $70 \%$ from the use of training programs is reported. Other authors (Brown, 1971; Snook et al., 1978) report no significant reduction, though the type of training being used was not specified. Back schools to assist workers with low-back pain to return to work have also been evaluated. One controlled study undertaken (Bergquist-Ullman and Larsson, 1977) reported a significant decrease in the length of time off the job among those injured workers participating in a back school versus other study participants. Back schools that attempt to prevent the first injury have also reported success (White, 1983) but without the controlled studies required to conclusively show training effectiveness (Troup, 1982).

Most studies have focused on a reduction in existing injury rates or improvement in recovery time after injury. Even though these are the most desirable end points, the studies do not isolate the effectiveness of the training per se. In fact, the investigators often have several strategies being used simultaneously to prevent low-back pain, and hence, the training effectiveness cannot be separated from other possible contributing factors. Further, the type of training used is often quite varied. In this context, the following ques- tions are often unanswered in the studies: Are just workers involved in the training, or are supervisors also involved? Is the training specific to the jobs, or is it general? Is reinforcement used. and if so, what type and how often? Do the workers have a history of lowback pain. or are they part of a physically fit, healthy population? All of these factors are believed to affect the training outcomes (Jones, 1985).

\section{OBJECTIVES}

This study seeks to evaluate the effectiveness of a specific worker training program as judged by resulting modifications in lifting postures of a select group of healthy warehouse workers. As such, the study is predicated on the belief that if training programs are actually to be effective as a means of preventing the occurrence of low-back pain, then to do so the training must be able to modify worker behaviours to a measurable degree. Therefore, the primary hypothesis to be tested was that a well-designed training program would result in significant changes in workers' lifting postures. To test this hypothesis it was necessary to develop a means to measure a large number of lifting postures used by warehoue workers.

\section{METHODS}

\section{Study design}

It was decided to conduct the study with a group of healthy workers. The basis for this is that if positive changes in the lifting behaviours of healthy workers can be demonstrated after training, then groups of workers who have a history of low-back pain would probably benefit even more from such training because of their increased motivation to change. Studying the effect of the training on 
healthy workers is also in keeping with the concept that training should be a means of preventing the first occurrence of low-back pain.

The site selected for the study was a warehouse. The workers in the warehouse manually sort boxes of goods and place them in trucks to be distributed to other locations. Thus, they are expected to prepare a pallet of different items by picking the items from shelves or pallets and placing them into boxes or directly on other pallets. Some of the workers studied handled bulk procedure to be distributed to various cafetarias in pallet loads. Once a pallet was prepared, it would be moved by a powered pallet mover into an area where the truck drivers would load their trucks.

The effectiveness of the training was measured before and after the training session by videotaping lifting postures used by workers performing their jobs, and comparing select postural attributes as visualized on the videotapes. The videotapes provided a record of a worker's lifting postures that could be viewed repeatedly to assure a correct classification of the postures.

The training program used was a commercially available program, modified to emphasize worker training, as opposed to supervisor training. The program selected was the "Pro-Back" * program from VISUCOM Productions Incorporated. This program was selected because it emphasized generally accepted biomechanical principles and made use of outstanding video graphic techniques to reinforce lifting concepts. VISUCOM personnel were willing to assist in modification of their program for this study. In presenting the program, the worker training was pro-

* The VISUCOM Low Back Pain Prevention Program, VISUCOM Productions, Inc., Box 5472, Redwood City, CA 94063, U.S.A. vided by a professional from the Center for Ergonomics who had experience and training in both adult education and biomechanics, and had attended the VISUCOM Pro-Back program.

\section{Description of worker training program}

An initial one-day supervisor training session was presented by VISUCOM personnel to the warehouse supervisors. This was done to familiarize the supervisors with the study, and gain their understanding of the need for their employees to handle loads in a fashion that would minimize low-back stress. The training included:

(1) Having the participants at the beginning of the training lift different size boxes used in the warehouse, and then discuss with them why they performed the lifting as they indicated.

(2) Showing and discussing three videotapes which emphasized, Basic biomechanics of lifting, Ergonomic modifications of the workplace, and Supervisor and worker roles in reducing low-back stresses.

(3) Reviewing written instructions and graphic aids given to the participants to help them understand how the lifting principles work, and how they can be applied in their operations.

(4) Having the participants try the lifting principles again, using boxes and a general workplace arrangement representative of that in the warehouse.

(5) Performing a written evaluation of the session, wherein the participants indicated what new knowledge they had gained.

From the discussion with the supervisors and their written comments, it was then decided to present two 4-hour training sessions to thirty-three of their workers. The videotape and discussion regarding the need for ergonomic job changes would not be included, and the training would be presented by a person from the Center for Ergonomics, who 
also attended the supervision training session, rather than the immediate supervisors. It was also decided that the supervisors would be supportive of the training, but would not reinforce specific lifting techniques when observed after the training. It should be noted that such reinforcement is an integral part of the normal VISUCOM program, but was not used in the study to allow the determination of the effect of a single, well presented, 4-hour training session on their workers:

The five principles continually emphasized during the training are:

(1) Get as close to the load a possible,

(2) Keep the torso as erect as possible,

(3) Don't lift and twist the torso while lifting,

(4) Lift smoothly, don't jerk the load, and

(5) Get a good grip on the object, and make sure the work area is as clear as possible of obstacles that could cause a slip or trip.

\section{Study group statistics}

A background survey of the study population revealed that of the 33 in the training group, $12 \%$ were female, and the group's average age was 35 years, with a range from 23 to 58 years. The average time spent on the job was four years, with a minimum of one year. All had completed high school. None admitted to having had low-back pain, and none had previous training in lifting techniques.

\section{Data collection and analysis procedure}

The initial filming of the workers took two weeks. Each person was informed that they were being filmed to determine stresses involved in their work as part of a NIOSH sponsored study. They were told that they would receive training on how they might perform their jobs to reduce low-back stresses, but were not told that they would be refilmed sometime later to determine how their lifting behaviour changed.

The videotaping procedure was simple. The analyst would choose a worker at random (or a worker who was doing a lot of lifting at the time) and follow him/her around, taping the worker whenever lifting. This was a lengthy process due to the fact that the workers did not always perform lifting (there was paperwork involved with most of the jobs). At least six lifts with different sizes, types, and weights of loads were taped for each worker. The weight of each object lifted was recorded during the taping for subsequent biomechanical analysis. The analysis attempted to position himself while taping so as to provide an unobstructed, nearly sagittal plane view of the worker while lifting.

The films were immediately viewed and the data shown in Fig. 1 were recorded. As can be seen in the data sheet, two types of postural data were obtained, discrete yes or no binary data, and continuous data regarding the horizontal distances to the load and the torso angle. The binary data were obtained with reference to the following decision criteria:

(1). Keeping it close. If the load wasn't as close to the body as possible, could the load or person have been closer? Was the distance to the load due to the workplace (i.e., the worker was lifting an object from a container or storage device that inhibited the lifting style). In most cases, it was obvious whether or not the load was as close as possible. In the few cases where it was not completely obvious, it was left to the personal judgment of the analyst.

(2). Keeping upper body erect. This meant that the torso angle shown in Fig. 2 was as close to vertical $\left(90^{\circ}\right.$ from the horizontal) as possible. If this was not the case, could the worker have moved closer and bent the knees more to accomplish it?

(3). Don't lift and twist. Was there a simultaneous "lift and twist"? Did the worker exert a lateral twisting motion before finishing the vertical lift? If so, could the worker have avoided this by taking an extra step? Could 


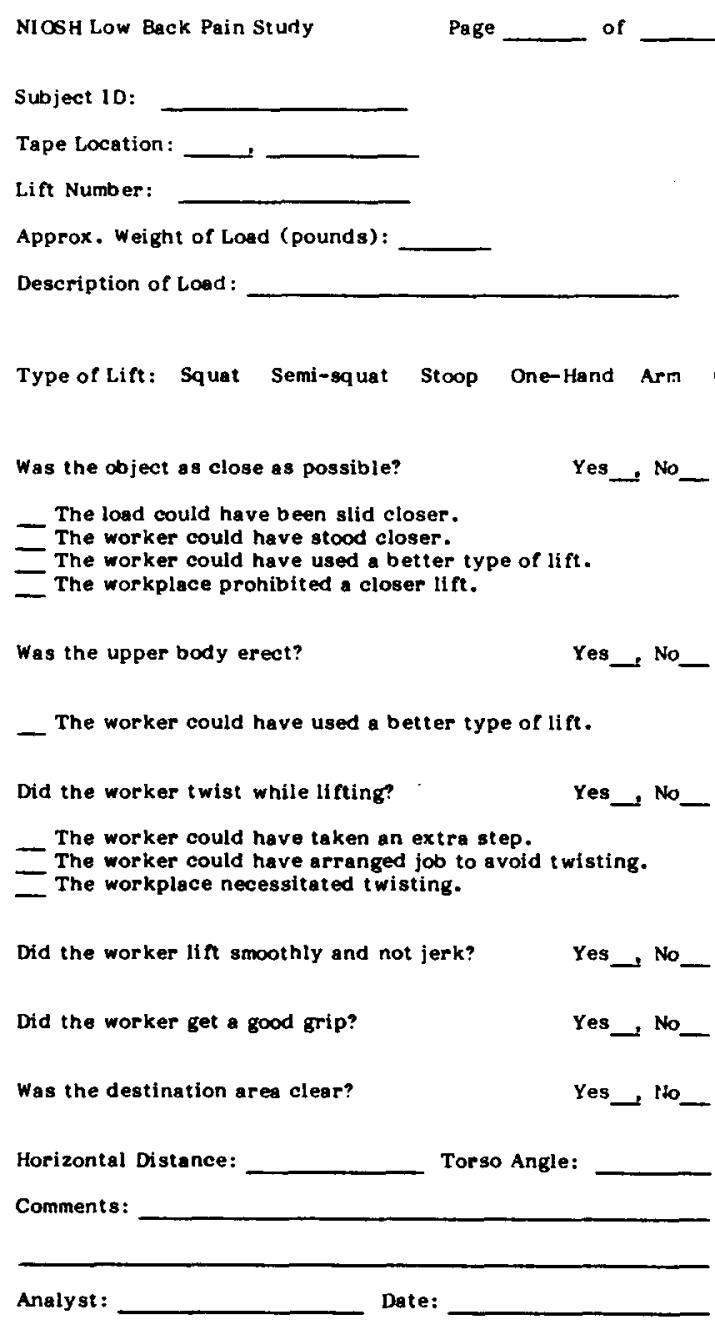

Fig. 1. Lift evaluation record form used by videotape analyst to record data on 324 lifts filmed in study.

the worker have arranged the job to avoid this? Was it due to the workplace?

(4). Lift smoothly, don't jerk. Was there a constant acceleration, and not a large "jerk" at the beginning of the lift?

(5). Get a good grip. Did the worker place his/her hands fully under or around an object (i.e., in a power grip) before lifting, as opposed to only using the distal parts of the fingers in a pinch type of grip?

The data regarding the destination area being clear of objects was not analyzed in the study, because this condition was most often the result of the workplace layout, and not the worker.

The two continuous variables (i.e., the horizontal distance and torso angle) were measured just as the object was beginning to move upward. The actual measurements were obtained by freeze-framing the tape at that point and measuring the distance and angle indicated in Fig. 2. Because the warehouse was heated and the study was performed in the spring, the workers wore light clothing which assisted in obtaining these measurements. Similar measurements were made by Park (1973) and were found to have a $\mathrm{Cov}=$ 5\% with repeated readings. The $H$ distance was calibrated in each frame using the object lifted as a size reference.

The second videotaping of the workers occurred from 35 to 51 days after the training session. Unfortunately some workers included in the first taping were not available for the second taping, and hence the data analysis could only be completed for 26 subjects. In total 174 lifts were analyzed before training and 150 lifts after training for the group of 26 workers.

The resulting data were statistically evaluated to determine the mean effect of the training. For the binary data a contingency test was performed to determine if the proportion of "yes" replies before training was the same as the proportion after training for each lifting criteria. For the two continuous variables a Smith-Satterthwaite Test of differences in the mean values of $H$ distance and torso angle before and after training was used.

Because a large range of loads were lifted by the workers during this study (see Fig. 3), an additional post-hoc analysis was possible. This analysis attempted to test the following hypothesis: Workers would move heavier loads closer to them and maintain a more vertical torso posture than when lifting lighter loads. To test this hypothesis, the loads lifted were stratefied into three groups: $U p$ to 10 


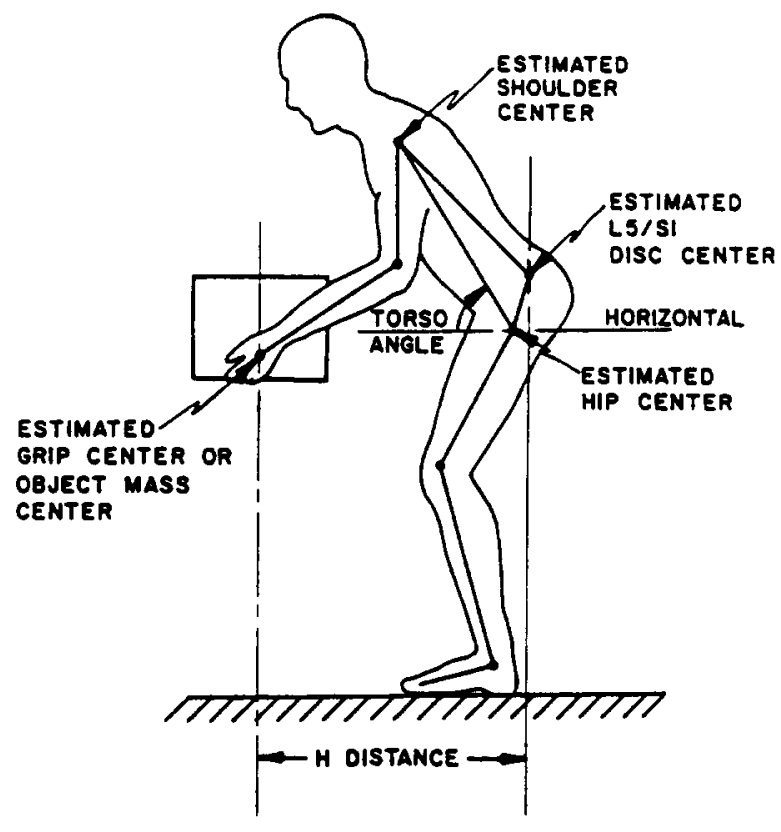

Fig. 2. Illustration of the two variables ( $H$ distance and torso inclination) measured in each of the 324 lifting situations studied.

pounds, representative of a very light load, between 10 and 35 pounds, representative of relatively light to moderate loads, and 35 to
45 pounds, which approximates loads at or slightly above the NIOSH Action Limit (NIOSH, 1981). A two-way Analysis of Variance was performed on these two continuous variables of horizontal distance and torso angle to determine if heavier loads were handled differently after and before training than the lighter loads. An alpha error of 0.05 was used to reject the hypothesis that the load would not affect the horizontal distance and torso angles.

A biomechanical analysis of the loads and postures was also performed using the Center for Ergonomics, Biomechanical Strength Model. This model predicts L5/S1 disc compression forces by assuming the body is a six link articulated system. When a load is applied to the end of the linkage (i.e., the hands) while the links are configured in a specific orientation (i.e., posture), the resultant moments at each joint is computed assuming static equilbrium conditions. The torso is assumed to be two links, articulated at the L5/S1 disc. The muscle force necessary to stabilize the torso linkage against the external resultant moment created by the load being

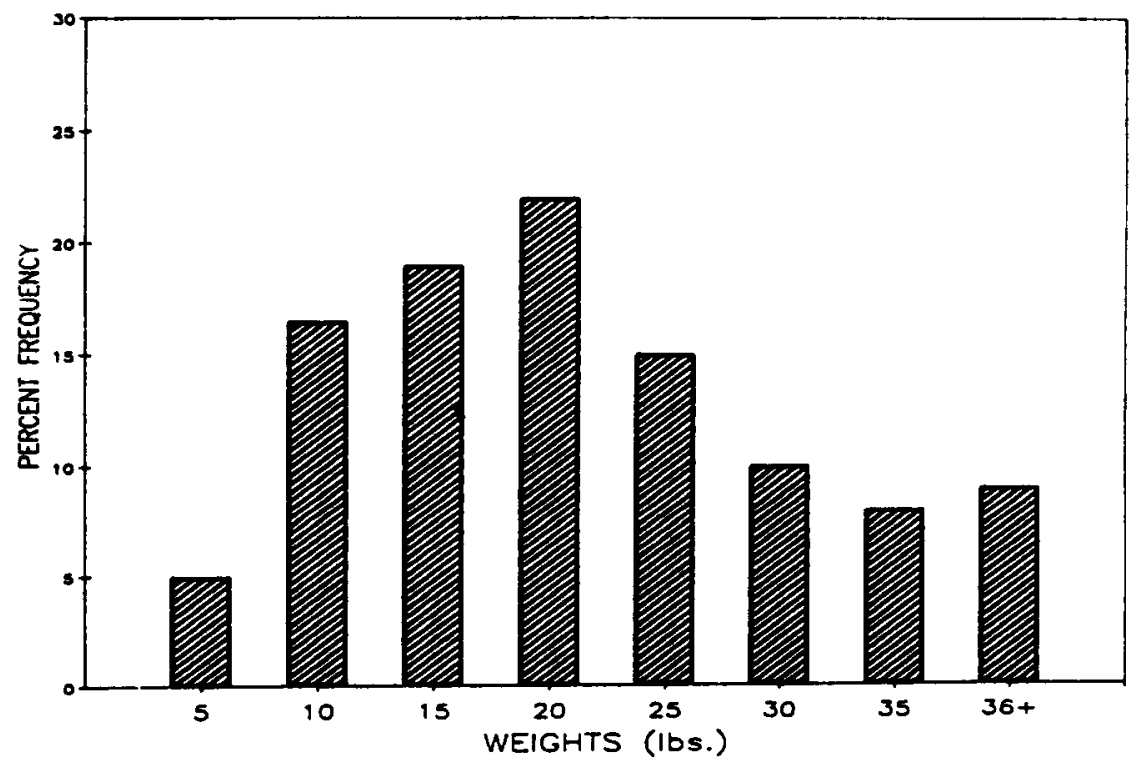

Fig. 3. Distribution of weights lifted in study. 
handled and body weight is estimated, and then used to predict the disc compression forces. A complete description of this model and algorithm is given in Chaffin and Andersson (1984). This analysis indicated that in less than $10 \%$ of the lifts studied the L5/S1 disc compression force exceeded the NIOSH Action Limit of 770 pounds compression. Therefore, in interpreting the results that follow, it must be acknowledged that they are applicable to relatively light load lifting conditions only.

\section{RESULTS}

The effect of training, as subjectively rated by the proportion of "yes" responses of the analyst on the evaluation form shown earlier (Fig. 1) is depicted in Table 1.

These results indicate that the training did have a beneficial effect on two of the five criteria used to judge lifting behaviours. The prevalence of jerking the loads was diminished from $21 \%$ to $2 \%$ of the lifts after training (significant at $\alpha<0.001$ level), and the prevalence of inadequate gripping of the objects was decreased from $11 \%$ to $1 \%$ after training (significant at $\alpha<0.001$ level). The analyst did not rate the workers as improved, however, by the other three criteria: keeping the load close, keeping the torso erect, and not twisting the torso. The workers did show a $5 \%$ decrease in the frequency of twisted torso lifting, but this was not statistically significant at $\alpha<0.05$ level.

The quantitative results from the analysis of how close the load was held (i.e., the $H$ distance at the beginning of the lift) and how erect the torso was (i.e., the torso angle at the beginning of the lift) is depicted in Table 2 . Recall that the analysis for the training effect was performed for three different load weight strata to determine if the weight had a differential effect before and after training (i.e., are heavier loads held closer with the torso erect after training than when lifting lighter loads?).

The quantitative results confirm the subjective impressions of the videotape analyst depicted in Table 1. In general, loads were not held closer nor was the torso held more vertically erect after training than before. The more detailed analysis did reveal a tendency

\section{TABLE 1}

Results of subjective evaluation of the effect of training on the five lifting criteria

\begin{tabular}{|c|c|c|c|}
\hline \multirow[t]{2}{*}{ Lifting criteria } & \multicolumn{2}{|c|}{ per cent of YES responses } & \multirow{2}{*}{$\begin{array}{l}\text { sig. level } \\
(\alpha)\end{array}$} \\
\hline & $\begin{array}{l}\text { before } \\
\text { training }\end{array}$ & $\begin{array}{l}\text { after } \\
\text { training }\end{array}$ & \\
\hline $\begin{array}{l}\text { Did the workers keep their } \\
\text { loads as close as possible? }\end{array}$ & 86 & 84 & $<0.30$ \\
\hline $\begin{array}{l}\text { Did the workers keep their } \\
\text { torso as erect as possible? }\end{array}$ & 86 & 85 & $<0.41$ \\
\hline $\begin{array}{l}\text { Did the workers twist their } \\
\text { torso while lifting? }\end{array}$ & 48 & 43 & $<0.22$ \\
\hline $\begin{array}{l}\text { Did the workers jerk the } \\
\text { load while lifting? }\end{array}$ & 21 & 2 & $<0.001$ \\
\hline $\begin{array}{l}\text { Did the workers have } \\
\text { inadequate grips while } \\
\text { lifting? }\end{array}$ & 11 & 1 & $<0.001$ \\
\hline
\end{tabular}


TABLE 2

Quantitative results of analysis of $H$ distance and torso angle at beginning of lifts for different load strata

\begin{tabular}{|c|c|c|c|c|c|}
\hline \multirow[t]{3}{*}{ Lifting criteria } & \multirow[t]{3}{*}{ Object weight } & \multicolumn{4}{|c|}{ Train effect on distance (in) degrees $\left({ }^{\circ}\right)$} \\
\hline & & \multicolumn{2}{|c|}{ before training } & \multicolumn{2}{|c|}{ after training } \\
\hline & & $\overline{\bar{X}}$ & $S D$ & $\overline{\bar{X}}$ & $S D$ \\
\hline $\begin{array}{l}\text { What was the } H \text { distance } \\
\text { at beginning of } \\
\text { lift with different loads? }\end{array}$ & $\begin{aligned} \leqslant & 10 \mathrm{lbs} \\
& 11-35 \mathrm{lbs} \\
> & 35 \mathrm{lbs}\end{aligned}$ & $\begin{array}{l}27 \\
23 \\
23\end{array}$ & $\begin{array}{l}7 \\
6 \\
7\end{array}$ & $\begin{array}{l}25 \\
23 \\
25\end{array}$ & $\begin{array}{l}6 \\
5 \\
4\end{array}$ \\
\hline $\begin{array}{l}\text { What was the torso angle } \\
\text { from horizontal at } \\
\text { the beginning of lift with } \\
\text { different loads? }\end{array}$ & $\begin{array}{l}\leqslant 10 \mathrm{lbs} \\
11-35 \mathrm{lbs} \\
>35 \mathrm{lbs}\end{array}$ & $\begin{array}{l}19 \\
29 \\
43\end{array}$ & $\begin{array}{l}23 \\
28 \\
26\end{array}$ & $\begin{array}{l}19 \\
30 \\
31\end{array}$ & $\begin{array}{l}29 \\
32 \\
32\end{array}$ \\
\hline
\end{tabular}

Note: The mean $\bar{X}$ values were not significantly different at alpha $<0.05$ level.

of the workers (both before and after training) to use a more vertical torso when handling heavier loads, $\left(19^{\circ}\right.$ for light load vs. $43^{\circ}$ or $31^{\circ}$ for heavier loads) though this was not statistically significant (at alpha $<0.05$ level).

\section{CONCLUSIONS AND DISCUSSION}

It is concluded from this study that a well planned and presented four-hour worker training program can have a significant but minimum effect on some lifting behaviours. Recall that this conclusiol. is based on a group of healthy workers (i.e., they acknowledged no history of back problems), and they were subjected to only moderate stresses on the low back during the study. Therefore, it is suggested that training may be useful as part of a more comprehensive program to prevent low-back pain from developing in such a work situation.

Further, it would appear that the type of lifting behaviours most susceptible to alteration are ones that are simple to learn (i.e., don't jerk or throw loads, and make sure you have a secure grip on an object). This study did not reveal any changes after the training session in the more critical aspects of torso inclination, twisting, and in moving closer to loads. It may be that these motor behaviours are more difficult to learn (i.e., they require well practiced manual skill and coordination to execute). Alternatively, often the workplace dictates how people must position themselves when lifting. The fact that the analyst subjectively concluded that the workers were as close to the load as possible before training, and were using as erect a torso as possible in about $85 \%$ of the 324 lifts studied, indicates that little improvement could be realized by the training without ergonomic changes in the workplace layout, object size, and handle locations. In contrast, twisting the torso while lifting can often be avoided by the person taking a side step-andturn motion with the load. A definite trend in using this technique was detected after the training, but was not statistically significant.

The quantitative analysis of $H$ distance and torso inclination angle did reveal that when handling the heavier loads the workers attempted to raise their torsos to a more vertical posture, both before and after training. Though this trend was not statistically significant, it does show a sensitivity in this group to the concept when handling heavier loads. As discussed previously, because of the 
layout of the warehouse and the size of the objects being handled, the torso inclination angle was restricted in most of the lifts analyzed. This simply points out the need for ergonomic improvements as well as training, as proposed by Snook et al. (1978).

Clearly this study did not deal with long term retention of the lifting concepts. One study by Hultman et al. (1984) of six healthy workers did show a three month retention of the concept to keep the torso more vertical while performing janitorial services. In this case the workers were shown and practiced new methods of performing their tasks in three separate 30 to 45 minute sessions over a two-week period. They were also repeatedly, formally quizzed on their knowledge to assure comprehension at the end of the training sessions. By having smaller groups, and short, separated training sessions, the workers were provided the opportunity to try the suggested techniques and then meet and receive further feedback and reinforcement from a skilled trainer. Such on-the-job practice and reinforcement is probably essential for long-term retention. In this regard, active involvement of the supervisors, as is part of the normal VISUCOM program used in this study, should assist in retention and perhaps further improvement in the lifting techniques in this warehouse.

Lastly, it is believed that this study demonstrates a practical and useful method of evaluating the lifting techniques employed in industry. A videotape combined with the evaluation form in Fig. 1 provide an excellent record for comparing the effectiveness of different types of intervention strategies, and thus can assist in determining the cause and prevention of occupational low back pain. Admittedly, the use of a video camera to record work activities may influence the work postures in some unknown way, but such an effect should be consistent before and after the intervention. In this study the workers were not aware that their lifting postures were being compared before and after training. To futher determine the potential effects of videotaping, one would have to find a workplace with similar ergonomic requirements and workers who could be evaluated as a control group. Perhaps larger studies of training effectiveness should include this extra precaution.

\section{ACKNOWLEDGMENTS}

The authors wish to acknowledge support for this study from NIOSH Order No. 84-3146 and to Dr. B. Kuchinski, project officer, for her encouragement in pursuing this project. Similarly, we thank Mr. Hugh Tirrell, President of VISUCOM for his assisting in developing the special training program used in this study. Also, we thank Messrs. E. Suckerstorff and H. Pattullo, Assistant General Managers of The University of Michigan Stores for their assistance in conducting this study. Lastly, we'd like to thank the men and women who willingly participated as subjects in this study.

\section{REFERENCES}

Bergquist-Ullman, M., and Larsson, U., 1977. Acute low back pain in industry. A controlled prospective study with special reference to therapy and confounding factors. Acta Orthop Scand (Suppl), 170: 1-117.

Biering-Sorenson, F., 1982. Low back trouble in a general population of 30-, 40-, 50- and 60-years old men and women. Study design, representativeness and basic results. Dan. Med. Bull., 29(6): 289-99.

Brown, J.R. 1971. Lifting as an industrial hazard. Labour Safety Council of Ontario, Ontario Department of Labour, Toronto.

Chaffin, D.B., and Andersson, G.B.J., 1984. Occupational Biomechanics. John Wiley \& Sons, New York.

Glover, J.R. 1976. Prevention of back pain. In: M. Jayson (Ed.), The Lumbar Spine and Back Pain. New York: Grune and Stratton.

G. Hultman, Nordin, M., and Ortengren, R. 1984. The influence of a preventive educational programme on 
trunk flexion in janitors. Applied Ergonomics, 15(2): 127-133.

Jones, D.F., 1985. Back injury prevention-Are our programs adequate?, Professional Safety, February, p. 18-24.

Miller, R.L., 1977. Bend you knees!, Nat. Safety News, May, 57-58.

National Institute for Occupational Safety and Health. 1981. Work Practices Guide for Manual Lifting. Technical report 81-122, Cincinnati, Ohio: Division of Biomechanical and Behavioral Science, NIOSH.

Park, K.S., 1973. A Computerized Simulation Model of Postures During Manual Materials Handling. Ph.D. Dissertation, The University of Michigan, University of Microfilms, Zeeb Rod, Ann Arbor, MI.

Snook, S.H., and Jensen, R.C., 1984. Cost. in: M.H.
Pope, J.W. Frymoyer, and G.B.J. Andersson, (Eds.), Occupational Low Back Pain, Praeger, New York, p. 115-121.

Snook, S.H., and White, A.H., 1984. Education and training in: M.H. Pope, J.W. Frymoyer, and G.B.J. Andersson, (Eds.), Occupational Low Back Pain. Praeger, New York, p. 233-244.

Snook, S.H., Campanelli, R.A., and Hart, J.W., 1978. A study of three preventive approaches to low back injury. J. Occup. Med., 20(7): 478-81.

Troup, D. 1982. Back injuries can be prevented, Health and Safety at Work, 5: 15-17.

White, A.H. 1983. Back Schools and Other Conservative Approaches to Low Back Pain, C.V. Mosby, St. Louis. 